\title{
Kinetic Analysis and Modelling of Mg Powder Slow Combustion
}

\author{
Guillaume Moser, Valérie Tschamber, Cornelius Schönnenbeck, Alain Brillard, Jean-François Brilhac \\ Université de Haute-Alsace, Laboratoire de Gestion des Risques et Environnement (EA2334) \\ 3bis rue Alfred Werner, 68200 Mulhouse, France \\ guillaume.moser@uha.fr; valerie.tschamber@uha.fr; cornelius.schonnenbeck@uha.fr, alain.brillard@uha.fr, \\ jean-francois.brilhac@uha.fr
}

\begin{abstract}
Future lack of fossil fuels and global warming prompt researches on new renewable sources of energy, especially for transportation. With high energy densities, metals appear to be good energy carriers. In this study, magnesium powder was used as fuel. In order to analyse the magnesium oxidation mechanism and extract kinetics parameters, thermogravimetric (TG) experiments were carried out. Influence of the particles size was investigated by oxidising two different Mg size fractions: 20-50 $\mu \mathrm{m}$ and 50-71 $\mu \mathrm{m}$. TG measurements were performed under synthetic air flow and at several heating rates (from 1 to $5{ }^{\circ} \mathrm{C} / \mathrm{min}$ ) from $30{ }^{\circ} \mathrm{C}$ to $900{ }^{\circ} \mathrm{C}$. The kinetic triplets (i.e. Arrhenius parameters and reaction model) of both size fractions were determined using a nonlinear model-fitting method. The Scilab software was used to perform this method. The activation energies were found to be $130 \mathrm{~kJ} . \mathrm{mol}^{-1}$ and $166 \mathrm{~kJ}^{-\mathrm{mol}^{-1}}$ for the 20-50 $\mu \mathrm{m}$ and 50-71 $\mu \mathrm{m}$ fractions respectively. Corresponding preexponential factors were $3.6 .10^{5} \mathrm{~s}^{-1}$ and $1.2 .10^{8} \mathrm{~s}^{-1}$ respectively. These Arrhenius parameters were obtained with the Prout-Tompkins reaction model which is the one that fits at best the experimental results. Prout-Tompkins model means that $\mathrm{Mg}$ particles seem to oxidise following an autocatalytic nucleation mechanism. The Avrami-Erofeev (A2) model, which is another nucleation model, gave also satisfying results for both size fractions.
\end{abstract}

Keywords: Reaction kinetics, Modelling, Magnesium particles oxidation, Heterogeneous combustion.

\section{Introduction}

Due to fossil fuels increasing scarcity and global climate change, it is widely recognised that we must transition to low-carbon society. In the transportation field, some alternatives already exist but are quite limited (i.e. electric and hydrogen fuel cell vehicles). To compete with fossil fuels, renewable energy sources need to have a high energy density, which is the actual problem of batteries and hydrogen fuel cells [1], [2]. With high energy densities, metal powders appear to be good candidates for low-carbon energy carriers, and got more attention these last years [3], [4]. Many aspects of metal combustion were investigated through the years, but large part of these work focused on high temperature systems with particles ignition [5]-[9]. Only few studies [10], [11] aimed to investigate the combustion of metal particles subjected to low heating rates, leading to an exclusively heterogeneous combustion, which could be named "slow combustion" (i.e. without ignition of the metal particles).

Chunmiao et al. (2013) and Nie et al. (2016) both used thermogravimetric analyses (TGA) to determine kinetic parameters of magnesium powder oxidation. Chunmiao [10] used $\mathrm{Mg}$ particles with a nominal size of $6 \mu \mathrm{m}$, and performed TGA experiments from ambient temperature up to $1000{ }^{\circ} \mathrm{C}$ with heating rates from 5 to $20{ }^{\circ} \mathrm{C} / \mathrm{min}$ under $\mathrm{O}_{2} / \mathrm{N}_{2}$ mixtures. He estimated mean apparent activation energy of $234 \mathrm{~kJ} / \mathrm{mol}$ using an integral isoconversional calculation method, but he did not interest in the preexponential factor or the conversion function associated to the reaction. Nie [11] worked with <45 $\mu \mathrm{m}$ and $<25 \mu \mathrm{m} \mathrm{Mg}$ particles. He carried out TG experiments from 350 to $650{ }^{\circ} \mathrm{C}$ in pure oxygen, at heating rates of 2,3 and $5{ }^{\circ} \mathrm{C} / \mathrm{min}$. Using a model-free isoconversional method, he calculated a value of $148 \mathrm{~kJ} / \mathrm{mol}$ for the activation energy, the preexponential factor was observed to be function of the oxide thickness, and the reaction seems to be rate limited by the diffusion trough the oxide layer.

The aim of this paper is to characterize the process of metal particles slow combustion under air, and to extract kinetic parameters. Magnesium was used as metal fuel since it is the $7^{\text {th }}$ most abundant element in the earth's crust [12]. Experiments were performed using thermogravimetric analysis (TGA) under synthetic air flow which fits well for the slow oxidation of magnesium powder study. The influence of the particles size was investigated. Kinetic parameters were calculated with a nonlinear model-fitting method (described by the ICTAC Kinetics Committee [13]), which is a computation method using the Scilab software. 


\section{Material and Methods}

The magnesium powder used for this study was supplied by Carl Roth® and has a high purity (>99.8 \%). The raw powder, with a particles size possibly less than $75 \mu \mathrm{m}$ according to the specification, was sieved with a RETSCH GmbH AS200 sieving machine and 20,50 and $71 \mu \mathrm{m}$ sieves. Two size fractions were obtained: 20-50 $\mu \mathrm{m}$ and $50-71 \mu \mathrm{m}$. The particles size distribution was determined accurately using a laser granulometer Malvern Mastersizer $2000(\lambda=532 \mathrm{~nm})$ coupled with Malvern Sirocco 2000M dry powder feeder. Each sample was analysed three times for the reproducibility, and both distributions in number and volume were calculated using the Fraunhofer method which is valid for particles larger than ten times the wavelength of the laser. The analyses showed good particles distribution, since the mean Sauter diameters $\mathrm{D}[3,2]$ for $20-50 \mu \mathrm{m}$ and $50-71 \mu \mathrm{m}$ were $39.9 \mu \mathrm{m}$ and $60.9 \mu \mathrm{m}$ respectively.

The morphology of the magnesium particles was observed through scanning electron microspcopy (SEM) imaging, and confirmed that particles were coarse and not spherical.

TGA experiments were performed using a TA Instrument ${ }^{\circledR}$ Q500 thermogravimetric analyser. Magnesium powder was loaded in alumina pans with an average mass of $3 \mathrm{mg}$, so the bottom of the pan was covered. The runs were conducted at constant heating rate from $30{ }^{\circ} \mathrm{C}$ to $900{ }^{\circ} \mathrm{C}$, under synthetic air $\left(20 \% \mathrm{O}_{2} / 80 \% \mathrm{~N}_{2}\right)$ flow of $3.6 \mathrm{NL}^{-1}$. Heating rates of 1 , 2, 3 and $5{ }^{\circ} \mathrm{C} \cdot \mathrm{min}^{-1}$ were used, and each experiment was reproduced at least twice. All the data (i.e. mass, temperature and time) were collected and taped on the TA Universal Analysis software.

XRD analyses were carried out on both 20-50 $\mu \mathrm{m}$ and 50-71 $\mu \mathrm{m}$ raw Mg particles, and on oxidized Mg samples, after TGA experiments. The measures were done between 30 and $70^{\circ} 2 \Theta$, using a $\mathrm{Cu} \mathrm{K}-\alpha 1$ radiation.

\section{Results and Discussion}

\subsection{Influence of the Particles Size on the Conversion Rate}

TG measurements give the evolution of the sample mass as function of the time (or the temperature with constant heating rate runs). According to the XRD and total mass gain measured after TG analyses, we assume that the initial sample was pure magnesium powder and the sample after oxidation in the TG device was pure magnesium oxide $\mathrm{MgO}$. Consequently, the extent of conversion $\alpha(\mathrm{T})$ could be calculated as follows:

$$
\alpha(T)=\frac{m(T)-m(0)}{m(\text { end })-m(0)}
$$

Where $\mathrm{m}(0)$ is the initial mass of the sample, $\mathrm{m}(\mathrm{end})$ is the final mass of the sample and $\mathrm{m}(\mathrm{T})$ is the sample mass at a given temperature. Conversion rate can then be derived from the extent of conversion. In that way, curves of the conversion rate versus the temperature could be plotted for both size fractions at different heating rates as shown on Fig. 1 (a and $b$ ).

The trends of the conversion rate curves are different between the $20-50$ and the $50-71 \mu \mathrm{m} \mathrm{Mg}$ fractions. The peak in the conversion rate for the smaller size fraction is wider but lower in intensity than the one of the bigger size fraction and is also slightly shifted to lower temperatures. That means the oxidation of $20-50 \mu \mathrm{m}$ particles begins at lower temperature than 50-71 $\mu \mathrm{m}$ particles, but once the oxidation started, bigger $\mathrm{Mg}$ particles burn faster than the small ones. For a given mass, the reaction surface is higher for a 20-50 $\mu \mathrm{m}$ sample than for a 50-71 $\mu \mathrm{m}$, which means probably more reaction sites where the oxidation can occur, so possibly a lower temperature of oxidation beginning for the 20-50 $\mu \mathrm{m}$ particles. 

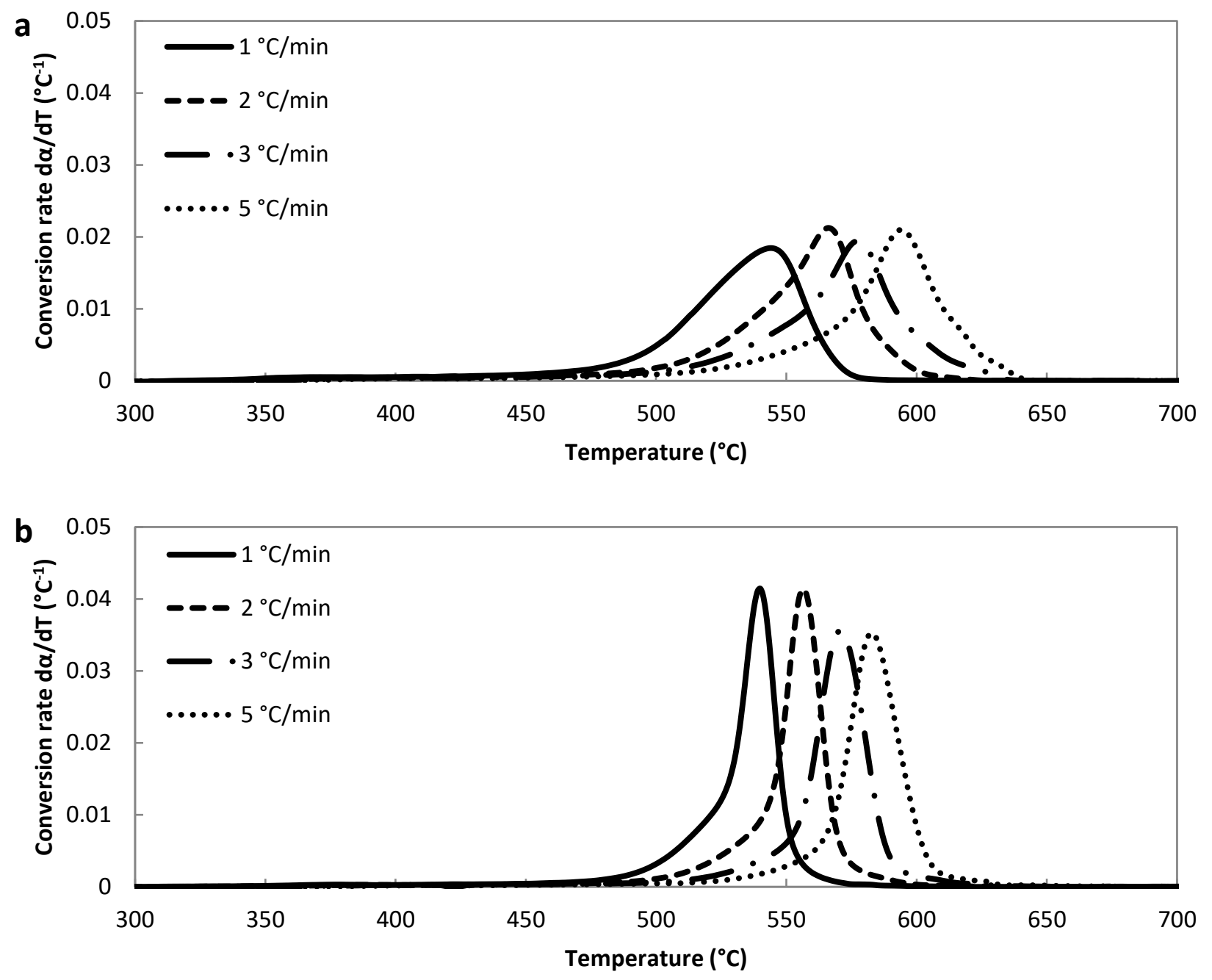

Fig. 1: Conversion rate versus temperature curves at different temperature programs, for 20-50 $\mu \mathrm{m} \mathrm{Mg}$ fraction (a) and 50-71 $\mu \mathrm{m} \mathrm{Mg}$ fraction (b).

\subsection{Kinetic Triplet Determination}

The kinetic parameters were determined according to the ICTAC Kinetics Committee publication [13], where a complete methodology is described to calculate and compute kinetic parameters from thermal analysis data. Briefly, the conversion rate for solid state reactions can be parameterized in terms of three major variables: the temperature $\mathrm{T}$, the extent of conversion $\alpha$, and the pressure P as follows:

$$
\frac{d \alpha}{d t}=k(T) * f(\alpha) * h(P)
$$

Where $k(T)$ is the rate constant given by an Arrhenius law, $f(\alpha)$ is the conversion function and $h(P)$ is a pressure dependence term. In the majority of cases, the last term is neglected when the gaseous reactant is in excess for gas-solid reaction [13]. We can consider oxygen as excess since the concentration is $20 \%$ in nitrogen, so the conversion rate is function of only two variables. Plus, with constant heating rate runs, the conversion rate can be described as a derivative with respect to the temperature, which gives the following expression: 


$$
\frac{d \alpha}{d T}=k(T) * f(\alpha) * \frac{1}{\beta}
$$

Where $\beta(=\mathrm{dT} / \mathrm{dt})$ is the heating rate. The rate constant, $\mathrm{k}(\mathrm{T})$, is defined according to an Arrhenius expression:

$$
k(T)=A * \exp \left(-\frac{E a}{R * T}\right)
$$

Where A and Ea are the kinetic parameters, respectively, the preexponential factor and the activation energy, and $\mathrm{R}$ is the universal gas constant. The conversion dependence term, $f(\alpha)$, can be expressed by a wide variety of reaction models. The choice of the model depends on the reaction profiles of TG curves. Three reaction profiles exist: accelerating, decelerating and sigmoidal [13]. But in the case of magnesium oxidation, accelerating profile was clearly excluded, since the conversion rate reaches a maximum and then slows down. Most commonly used reaction models are listed in Table 1, with Avrami-Erofeev and Prout-Tompkins as sigmoidal reaction profiles; $\mathrm{n}^{\text {th }}$ order, diffusion and contracting as decelerating reaction profiles.

Table 1: Main solid/gas reaction models and associated $\mathrm{f}(\alpha)$ conversion functions [13].

\begin{tabular}{|c|c|c|}
\hline Model & Acronym & $\mathbf{f}(\boldsymbol{\alpha})$ conversion function \\
\hline Avrami-Erofeev & A2 & $f(\alpha)=2(1-\alpha)[-\ln (1-\alpha)]^{1 / 2}$ \\
\hline Avrami-Erofeev & A3 & $f(\alpha)=3(1-\alpha)[-\ln (1-\alpha)]^{2 / 3}$ \\
\hline Avrami-Erofeev & A4 & $f(\alpha)=4(1-\alpha)[-\ln (1-\alpha)]^{3 / 4}$ \\
\hline Prout-Tompkins & B1 & $f(\alpha)=\alpha(1-\alpha)$ \\
\hline Mampel 1 st $^{3 / 4}$ order & F1 & $f(\alpha)=(1-\alpha$ \\
\hline $2^{\text {nd }}$ order & F2 & $f(\alpha)=(1-\alpha)^{3}$ \\
\hline $3^{\text {rd }}$ order & F3 & $f(\alpha)=1 /(2 \alpha)$ \\
\hline 1-D diffusion & D1 & $f(\alpha)=-1 / \ln (1-\alpha)$ \\
\hline 2-D diffusion & D2 & $f(\alpha)=1.5 *(1-\alpha)^{2 / 3} /\left(1-(1-\alpha)^{1 / 3}\right)$ \\
\hline 3-D diffusion & D3 & $f(\alpha)=3(1-\alpha)^{1 / 2}$ \\
\hline Contracting area & R2 & $f(\alpha)$ \\
\hline Contracting volume & R3 & \\
\hline
\end{tabular}

In order to determine the values of the Arrhenius parameters and the reaction model that fits best with the experimental data, the nonlinear model-fitting method described in the ICTAC publication [13] was applied. The principle of this nonlinear regression is to minimize the difference between experimental and simulated data. The method of least squares calculates the error in the form of the residual sum of squares:

$$
\text { error }=\sum\left(\left(\frac{d \alpha}{d T}\right)_{e x p}-\left(\frac{d \alpha}{d T}\right)_{s i m}\right)^{2}
$$

Where $\left(\frac{d \alpha}{d T}\right)_{\text {exp }}$ is the experimental conversion rate and $\left(\frac{d \alpha}{d T}\right)_{s i m}$ is the simulated conversion rate. The required data to execute the method are the experimental values of the conversion rate, measured by the TG experiments, and the simulated values of the conversion rate. A Scilab program was created in order to generate simulated data through the datafit algorithm. The program finds the optimal values of kinetics parameters (A and Ea) by minimizing the error given in Eq. (5). However, Vyazovkin et al. [14] showed that model-fitting is reliable, only if the models are fitted simultaneously to multiple experimental data sets obtained under different temperature programs (i.e. different heating rates). In our case, the Scilab program was adapted to fit the model simultaneously to four data sets with different heating rates $(1,2,3$ and 5 $\left.{ }^{\circ} \mathrm{C} . \mathrm{min}^{-1}\right)$. Simulated conversion rate data are calculated as follows: 


$$
\left(\frac{d \alpha}{d T}\right)_{s i m, i}=A_{s i m} * \exp \left(\frac{-E a_{\text {sim }}}{R * T_{\text {exp }, i}}\right) * \frac{f\left(\alpha_{\text {exp }, i}\right)}{\beta_{i}}
$$

In Eq. (6), the index $\mathrm{i}$ denotes the four temperature programs. $\mathrm{A}_{\text {sim }}$ and $\mathrm{Ea}_{\text {sim }}$ are, respectively, the simulated preexponential factor and activation energy calculated with the datafit routine. $T_{\text {exp, } i}$ and $\alpha_{\text {exp, } i}$ are the experimental data used for the computation of the simulated conversion rates. All conversion functions listed in Table 1 were tested with this method, and the simulation was carried out with experimental data sets of both 20-50 $\mu \mathrm{m}$ and 50-71 $\mu \mathrm{m}$ fractions. For each reaction model tested in the Scilab simulation, the kinetic parameters couple (A and Ea) and the error were calculated. Some of the simulated values are gathered in Table 2. To compare the results with each other, relative errors are expressed in the table as the error of the model divided by the minimal error (i.e. B1 model's error).

Table 2: Kinetic triplets and corresponding errors determined with the Scilab simulation.

\begin{tabular}{|c|c|c|c|c|c|}
\hline Size fraction & Reaction model & $\begin{array}{c}\text { Preexponential } \\
\text { factor }\left(\mathrm{A}, \mathrm{s}^{-1}\right)\end{array}$ & $\begin{array}{c}\text { Activation energy } \\
\left(\text { Ea, } \text { kJ.mol }^{-1}\right)\end{array}$ & error & relative error \\
\hline \multirow{5}{*}{$20-50 \mu \mathrm{m}$} & B1 & $3.6 \mathrm{E}+05$ & 130 & 6.18E-04 & 1.00 \\
\hline & A2 & $1.4 \mathrm{E}+06$ & 149 & 6.99E-04 & 1.13 \\
\hline & $\mathrm{F} 1$ & $1.7 \mathrm{E}+09$ & 194 & $2.17 \mathrm{E}-03$ & 3.52 \\
\hline & R3 & $3.1 \mathrm{E}+07$ & 176 & $2.13 \mathrm{E}-03$ & 3.45 \\
\hline & D2 & $1.9 \mathrm{E}+10$ & 223 & $1.77 \mathrm{E}-02$ & 28.71 \\
\hline \multirow{5}{*}{$50-71 \mu \mathrm{m}$} & B1 & $1.2 \mathrm{E}+08$ & 166 & 3.31E-03 & 1.00 \\
\hline & $\mathrm{A} 2$ & $7.2 \mathrm{E}+08$ & 188 & $6.34 \mathrm{E}-03$ & 1.91 \\
\hline & F1 & $2.1 \mathrm{E}+10$ & 210 & $2.09 \mathrm{E}-02$ & 6.31 \\
\hline & R3 & $2.6 \mathrm{E}+09$ & 205 & $1.56 \mathrm{E}-02$ & 4.72 \\
\hline & D2 & $1.0 \mathrm{E}+11$ & 236 & $6.70 \mathrm{E}-02$ & 20.23 \\
\hline
\end{tabular}

For both size fractions, the conversion function giving the lowest error is the Prout-Tompkins (B1) reaction model. Values of preexponential factor and activation energy found with this model are $3.59 .10^{5} \mathrm{~s}^{-1}$ and $130 \mathrm{~kJ}^{-\mathrm{mol}^{-1}}$ respectively for the $20-50 \mu \mathrm{m}$ fraction, and $1.15 .10^{8} \mathrm{~s}^{-1}$ and $166 \mathrm{~kJ}^{\mathrm{mol}}{ }^{-1}$ respectively for the $50-71 \mu \mathrm{m}$ fraction. The second best reaction model is the Avrami-Erofeev (A2) which gives kinetics parameters values higher than the Prout-Tompkins model. Fig. 2 ( $\mathrm{a}$ and b) compares experimental conversion rate curves and simulated conversion rate curves (with A2 and B1 models), for 1 and $5{ }^{\circ} \mathrm{C} \cdot \mathrm{min}^{-1}$ temperature programs. The curves obtained with the other models are not shown here since the errors are quite important, the curves do not really fit the experimental ones. Hence, it can be assumed that the oxidation mechanism of magnesium particles is closed to the ones described by the Avrami-Erofeev or Prout-Tompkins models, which are both nucleation models [15]. These models assume that the raw $\mathrm{Mg}$ particles present imperfections with local lower activation energy, which are called nucleation sites. The magnesium oxidation occurs on these nucleation sites, and provoke nuclei growth. The subtlety between both models is that Pout-Tompkins is an autocatalytic model, which means that the $\mathrm{MgO}$ nuclei growth promotes the formation of new nucleation sites. However, disparities between the model curves and the experimental ones are observable. They can be explained by the fact that we consider the oxidation process as a single-step reaction, whereas a multi-step reaction might actually occur. Further investigations should be done, the complexity being to distinguish the different steps. 

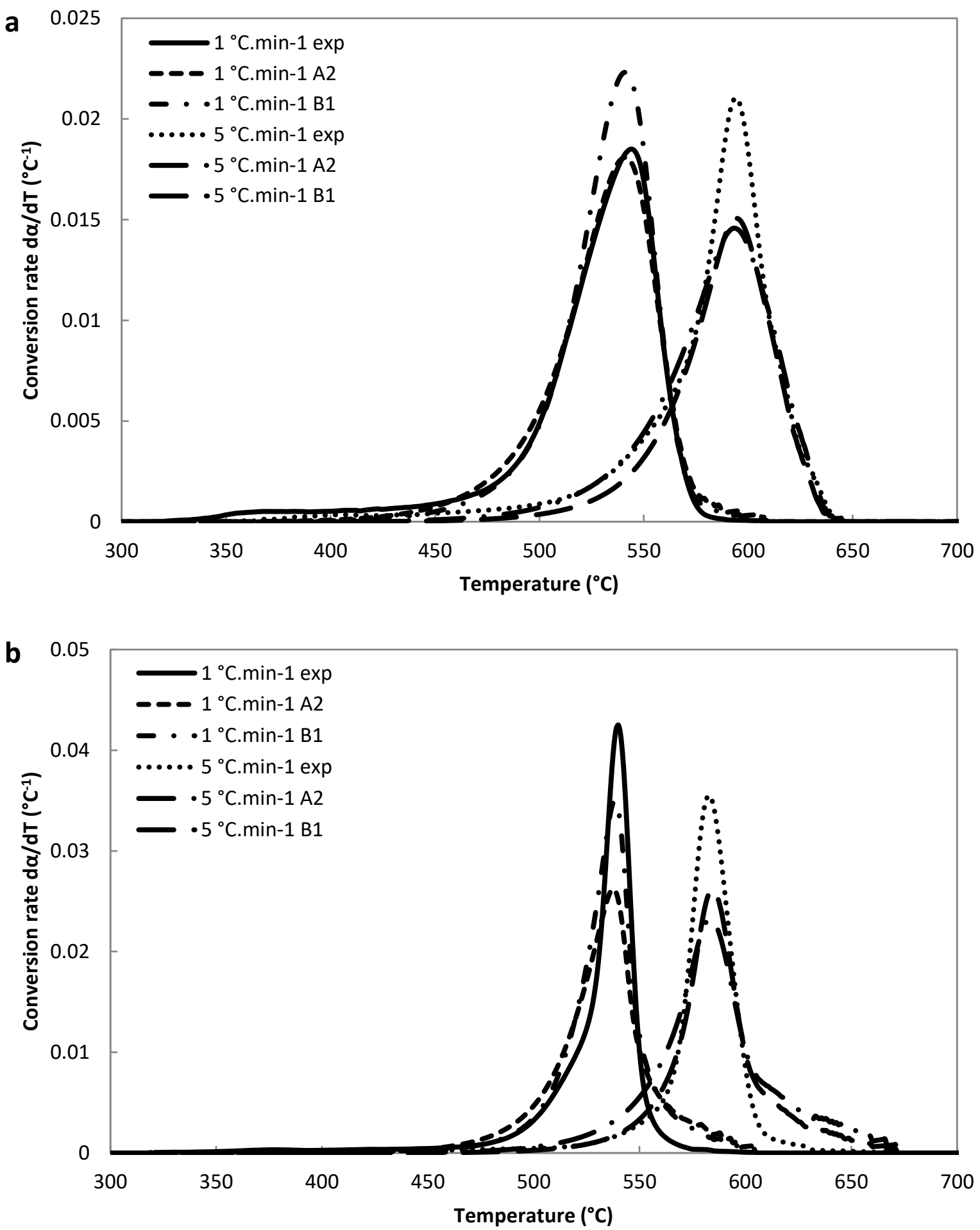

Fig. 2: Comparison of experimental conversion rates and simulated conversion rates for 20-50 $\mu \mathrm{m}$ fraction (a) and 50-71 $\mu \mathrm{m}$ fraction (b).

\section{Conclusion}

Metal powders have shown quite recently interest as potential renewable sources of energy for the transition to a lowcarbon society. The reaction kinetics and mechanisms of metal combustion are still misunderstood, although they are 
crucial to control the process. In the present study, the slow combustion (i.e. heterogeneous combustion without ignition of the sample) of two size fractions of $\mathrm{Mg}$ particles was investigated through thermogravimetric measurements. The kinetic triplets (activation energy, preexponential factor and reaction model) were determined using the nonlinear model-fitting method described by the ICTAC Kinetics Committee. For both size fractions, the reaction model that fitted the best with the experimental results was the Prout-Tompkins model, which involves an autocatalytic nucleation mechanism. With this reaction model, activation energies and preexponential factors were found to be, respectively, $130 \mathrm{~kJ} . \mathrm{mol}^{-1}$ and $3.6 \mathrm{e}^{5} \mathrm{~s}^{-1}$ for the $20-50 \mu \mathrm{m}$ fraction; and $166 \mathrm{~kJ} . \mathrm{mol}^{-1}$ and $1.2 \mathrm{e}^{8} \mathrm{~s}^{-1}$ for the $50-71 \mu \mathrm{m}$ fraction. These observations seem to show that the oxidation reaction starts at lower temperatures when the particles are smaller. But once the reaction started, the conversion rate increases faster for bigger particles. Further investigations need to be done to better understand the oxidation mechanism of magnesium particles, but that work gives precisions concerning the influence of the particles size on the kinetic.

\section{References}

[1] B. Diouf and R. Pode, "Potential of lithium-ion batteries in renewable energy," Renew. Energy, vol. 76, pp. 375-380, 2015.

[2] H. T. Hwang and A. Varma, "Hydrogen storage for fuel cell vehicles," Curr. Opin. Chem. Eng., vol. 5, pp. 42-48, 2014.

[3] J. M. Bergthorson et al., "Direct combustion of recyclable metal fuels for zero-carbon heat and power," Appl. Energy, vol. 160, pp. 368-382, 2015.

[4] P. Garra et al., "Magnesium/air combustion at pilot scale and subsequent PM and NOx emissions," Appl. Energy, vol. 189, pp. 578-587, 2017.

[5] H. M. Cassel and I. Liebman, "Combustion of magnesium particles I," Combust. Flame, vol. 6, pp. 153-156, 1962.

[6] G. H. Markstein, "Heterogeneous reaction processes in metal combustion," Symp. Int. Combust., vol. 11, no. 1, pp. 219-234, 1967.

[7] C. K. Law and F. A. Williams, "Combustion of magnesium particles in oxygen-inert atmospheres," Combust. Flame, vol. 22, no. 3, pp. 383-405, 1974.

[8] S. C. Li, F. A. Williams, and F. Takahashi, "An investigation of combustion of boron suspensions," Symp. Int. Combust., vol. 22, no. 1, pp. 1951-1960, 1989.

[9] V. Rosenband, A. Gany, and Y. M. Timnat, "Magnesium and Boron Combustion in Hot Steam Atmosphere," Def. Sci. J., vol. 48, no. 3, pp. 309-315, 2013.

[10] Y. Chunmiao, Y. Lifu, L. Chang, L. Gang, and Z. Shengjun, "Thermal analysis of magnesium reactions with nitrogen/oxygen gas mixtures," J. Hazard. Mater., vol. 260, pp. 707-714, 2013.

[11] H. Nie, M. Schoenitz, and E. L. Dreizin, "Oxidation of Magnesium: Implication for Aging and Ignition," J. Phys. Chem. C, vol. 120, no. 2, pp. 974-983, 2016.

[12] CRC Handbook of Chemistry and Physics, 89th ed. CRC Press, 2008. [Online]. Available: https://www.crcpress.com/CRC-Handbook-of-Chemistry-and-Physics-89th-Edition/Lide/p/book/9781420066791

[13] S. Vyazovkin, A. K. Burnham, J. M. Criado, L. A. Pérez-Maqueda, C. Popescu, and N. Sbirrazzuoli, "ICTAC Kinetics Committee recommendations for performing kinetic computations on thermal analysis data," Thermochim. Acta, vol. 520, no. 1-2, pp. 1-19, 2011.

[14] S. Vyazovkin and C. A. Wight, "Model-free and model-fitting approaches to kinetic analysis of isothermal and nonisothermal data," Thermochim. Acta, vol. 340, pp. 53-68, 1999.

[15] A. Khawam and D. R. Flanagan, "Solid-State Kinetic Models: Basics and Mathematical Fundamentals," J. Phys. Chem. B, vol. 110, no. 35, pp. 17315-17328, 2006. 